\title{
Ricardo CANO GaViria: UN ESCRITOR NECESARIO*
}

\author{
Ricardo Cano Gaviria: a Necessary \\ WRITER
}

Pablo Montoya Campuzano ${ }^{1}$

\footnotetext{
Texto leído en la entrega del títuto de Doctor Honoris Causa en Literatura de la Universidad de Antioquia a Ricardo Cano Gaviria, el 9 de mayo de 2019.

Cómo citar esta conferencia: Montoya Campuzano, P. (2019). Ricardo Cano Gaviria: un escritor necesario. Estudios de Literatura Colombiana 45, pp. 179-184. DOI: https://doi.org/10.17533/udea.elc.n45a10

pablojmontoya@yahoo.com

Universidad de Antioquia, Colombia

Recibido: 10.05 .2019

Aprobado: 11.05.2019
}

Copyright: $\odot 2019$ Estudios de Literatura Colombiana. Este es un artículo de acceso abierto distribuido bajo los términos de la Licencia Creative Commons Atribución No comercial - Compartir igual 4.0 Internacional

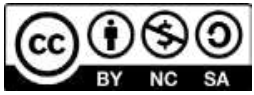

Lo primero que leí de Ricardo Cano Gaviria es un relato llamado "En busca del Moloch". Vivía en París en ese entonces y alguien me recomendó a este escritor a través de un adjetivo que recuerdo muy bien: raro. Abrí los ojos con sorpresa y se me explicó que raro tenía que ver con un tipo de escritores que Rubén Darío había señalado para expresar la condición incómoda o extraña de su literatura. Era algo así como autores y obras que se separan de una moda literaria, o que son ajenos a una tradición triunfante, o que representan choques y rupturas, y por lo tanto no entran fácilmente en clasificaciones hermenéuticas.

La obra de Cano Gaviria, sus cuentos y novelas en los que se levantan puentes entre Colombia y Francia, o más bien entre América y Europa, podría caracterizarse con el rótulo que propuso Rubén Darío. Por tal motivo, ella se enlaza a una tradición que se nutre del modernismo, tanto del latinoamericano como del europeo. Cano Gaviria es un heredero de un modernismo que, por la evolución misma de la literatura colombiana a partir del boom, se ha tornado cada vez más extraño, por no decir más insular y oculto. Y del que parte Cano Gaviria lo representa muy especialmente José Asunción Silva. Este poeta no solo le ha dado una suerte de carta de navegación, sino que Cano Gaviria ha sido consciente - de allí el ensayo biográfico que le dedicó- de lo importante que fue el acto de Silva al querer ser cosmopolita, incómodamente cosmopolita, en un país sumido y cercado a la sazón por realismos de corte costumbrista. 
Ahora bien, ante un panorama como el que viene ofreciendo la literatura colombiana después de la entronización internacional del modelo literario de García Márquez y sus epígonos periodistas, lo que se aleje de este y se enraíce o se proyecte en otras coordenadas culturales o en otras propuestas literarias, asume de inmediato entre nosotros la condición de raro y marginal. Y no cabe duda de que esta distinción Honoris Causa que la Universidad de Antioquia le otorga a Ricardo Cano Gaviria a través de su Doctorado en Literatura reside en parte a que su obra es justamente rara, marginal, distinta en el panorama de nuestras letras.

Pero quisiera volver al relato a partir del cual empecé a leer a Cano Gaviria. Moloch, recuérdese, fue una deidad de los pueblos antiguos de Asia Menor. Babilonios, caldeos, cartagineses y fenicios le rindieron culto sabiendo que era un dios del trueno, del fuego, de la guerra. En el relato de Cano Gaviria, Moloch está asociado al modo en que Flaubert lo elabora en su novela Salambó. Moloch devora niños, adolescentes, jóvenes, y no solo Flaubert, sino Cano Gaviria, se apropian de los holocaustos humanos que le son ofrecidos para decirnos que Moloch, desde tiempos inmemoriales, está vivísimo en las maneras en que las sociedades humanas se comportan. El relato de Cano Gaviria utiliza un modo elusivo, si se quiere, para mostrarnos que el horror de la guerra no está en los conflictos bélicos que padece Francia, sino también en las guerras civiles colombianas del siglo XIX. A través de una imaginada correspondencia entre Gustave Flaubert y Carolina Tovar, una santafereña que hace todo lo posible para que el escritor francés venga a Colombia y pueda escribir libre de las turbulencias en que está sumida Europa, "En busca del Moloch" manifiesta no solo esta continuidad de una violencia histórica, sino también las maneras en que Cano Gaviria ha construido su obra literaria.

En primer lugar, se presenta el vínculo entre Europa y América, en este caso entre Francia y Colombia, a través de escritores y lectores. En el relato mencionado están Gustave Flaubert y su admiradora lectora de este lado del océano, pero también aparecen en otros textos Charles Baudelaire, Victor Hugo, Marcel Proust, Jean Paul Sartre y Walter Benjamin. Así, lo que se encuentra en la obra de Cano Gaviria es una constelación de escritores que conforman no solo una familia literaria, sino un lenguaje, una atmósfera, un ethos, un pathos, una amatoria que modelan unos personajes, unos tiempos y unos espacios inquietantemente universales. 
¿Por qué, valdría la pena preguntarse, se ha dado este itinerario en Cano Gaviria? ¿Por qué un escritor nacido en Medellín, que es uno de los núcleos más fuertes del proyecto narrativo de lo regional como mejor expresión de la literatura colombiana, decide romper con una forma de hacer y comprender la literatura que en Tomás Carrasquilla tiene tal vez su mayor baluarte? ¿Por qué, para ser más precisos, esta senda que arranca de la Medellín conservadora y católica de los años sesenta para abrirse o precipitarse o extraviarse en la literatura europea de finales del siglo xIX e inicios del $\mathrm{xx}$ ? Una posible respuesta es que para convertirse en el escritor que es Cano Gaviria ha tenido que desterritorializarse. Lo cual significa poner en crisis lo que está, de hecho, ya atravesado por la crisis. Es decir, un individuo, una ciudad, un país, una cultura. Significa desestabilizar aquellos terrenos donde lo nacional se siente tan a gusto. Significa dejar entrar a la escritura otros imaginarios, otras lenguas, otras problemáticas geopolíticas, y así sugerir que Colombia es, desde que nació como país, una parte bastante azarosa y conflictiva del todo planetario. Y significa, por último, asumir un dolor, un dolor que a veces es epifánico: el dolor del perpetuo desarraigado.

Y es que, me atrevería a decir, los personajes mayores de Cano Gaviria son desarraigados incurables. No solo el escritor Flaubert de "En busca del Moloch"; sino el filósofo suicida de El Pasajero Walter Benjamin; o los dos personajes, Héctor y Rolando, que paladean su exilio, entre desolados y felices, en La puerta del infierno; o los otros dos hombres de Una lección de abismo, Jasmin y Robert que, creyéndose jóvenes y afortunados, solo dan vueltas en torno a los vacíos del amor y la muerte. Esta coyuntura, la del desarraigo, no es fácil vivirla. El precio es por lo general muy alto. Pero sospecho que vale la pena llevarla a cabo porque de algún modo escribir a contracorriente, y si se hace bien, con la responsabilidad que genera todo acto de escritura, es decir con la certeza de que este se apoya en un estilo, resulta siendo un acto liberador. $\mathrm{O}$ al menos una actividad del pensamiento, del cuerpo, de la imaginación que abre el horizonte a otros caminos y a otras posibilidades de la expresión literaria. Y esta es, me permito precisarlo, otra de las razones por las cuales nosotros, los profesores del Doctorado en Literatura, propusimos el Honoris Causa a Cano Gaviria a las altas autoridades académicas de la Universidad de Antioquia. Porque su obra ayuda a quitarnos, en tanto que lectores, críticos y creadores, las incómodas cadenas que nos han impuesto los regionalismos 
y los nacionalismos literarios colombianos y latinoamericanos. Con Cano Gaviria, al leerlo con atención y regocijo, entendemos, y esto lo ha aprendido él, tal vez de Borges, pero quizás también de Baldomero Sanín Cano, que los imaginarios literarios para poder avanzar, si urgen de trabas y cadenas, es para enfrentarlas y superarlas. Y no me parece disparatado del todo suponer que si Tomás Carrasquilla estuviese aquí, en este recinto, o mejor, en esta Alma Mater, por la que pasó un tiempo como estudiante de derecho, un tiempo quizás tan breve como el que pasó Ricardo Cano Gaviria como estudiante de sociología, terminaría por aceptar, luego de lanzar una mirada al entorno de nuestros días, que uno de los objetivos mayores, quiero decir uno de los más liberadores, de toda literatura que nace como expresión de lo nacional es justamente desprenderse de esos principios de raza, lengua, religión, ideología que han manipulado con tanta frecuencia a los autores y a los lectores.

La crítica que se ha ocupado de la obra de Ricardo Cano Gaviria ha entendido que la suya, como pocas en la literatura colombiana, está profundamente anclada en el fenómeno literario. "Sus páginas —al decir de Eduardo Jaramillo Zuluaga - están siempre transidas de literatura". Quienes escriben en sus libros son escritores que saben que la lectura es el motor fundamental no solo de sus vidas, sino del devenir más apasionante de las civilizaciones occidentales. Entendemos que lectura y escritura van de la mano en los avatares de la educación y la recreación. Que las grandes religiones monoteístas son librescas. Que las constituciones políticas de las naciones son documentos escritos. Pero lo llamativo en la obra de Cano Gaviria es que la lectura y la escritura se asumen como armas o escudos en continuos estados de emergencia. De tal manera que sus personajes son conscientes de que les ha tocado vivir en tiempos difíciles. Y que, como se dice en esa extraordinaria novela que él dedico al último día de Walter Benjamin, "es ante la proximidad de la borrasca, en la vecindad del peligro, cuando el complejo velamen de las vidas espirituales se siente navegar en la plenitud de sus posibilidades".

Este cosmopolitismo entusiasta y al mismo tiempo lancinante, este ámbito complejamente literario, estos personajes lábiles que combaten denodadamente por su libertad en medio del espanto, es lo que, tal vez, torna los libros de Cano Gaviria tan inolvidables como marginales.

$\overline{2 \quad J a r a m i l l o ~ Z u l u a g a ~ E . ~(1992) . ~ L e c t o r ~ q u e ~ e s c r i b e . ~ B o l e t i ́ n ~ C u l t u r a l ~ y ~ B i b l i o g r a ́ f i c o ~ 29 ~(29), ~}$ pp. 134-138. 
Y quiero resaltar, con la palabra marginal, que las tramas de sus libros, además, suceden en lugares ajenos a los centros de poder. Pero es el poder y sus formas de actuar lo que, finalmente, se va trasluciendo mientras leemos sus libros. El fascismo de la segunda guerra mundial y sus acosos, vistos a través de un hombre enfermo que huye por unas fronteras geográficas que se cierran inexorablemente, como sucede en El pasajero Walter Benjamin. La guerra como mal histórico, atada a la construcción de las naciones, reflejada en una correspondencia entre aquel célebre escritor francés y una desconocida dama santafereña, como ocurre en "En busca del Moloch". Mayo del 68, la liberación sexual de una generación de jóvenes inteligentes pero exacerbados, los problemas de las fragorosas militancias juveniles revolucionarias de la Colombia de esos mismos años, expresados a través de un diálogo delirante de dos colombianos en varios bares de París, como sucede en La puerta del infierno. Magistral muestra de un excentricismo literario que, al proponernos escapes y líneas de fuga, termina por arrojarnos al centro mismo de los infortunios.

Al lado de esta obra que ha sido escrita desde afuera y en silencio, ajena a los patrocinios de los grandes padrinos del poder político y literario, aspecto que sin duda la hace más respetable y digna, Cano Gaviria ha emprendido una labor de crítico y de editor que resulta encomiable. Su obra crítica permanece dispersa en varias revistas y periódicos de América Latina y Europa, y está a la espera de ser recogida y publicada. Y la segunda se condensa en la editorial Igitur, que Ricardo Cano Gaviria y su esposa Rosa Lentini dirigen desde hace años. Los libros publicados por Igitur han sido ese lugar al que muchas veces hemos ido, con la sensación del sediento que busca el manantial, para leer las grandes voces de la poesía del siglo xx, desde Giuseppe Ungaretti y Eugenio Montale hasta Osip Mandelstam y Philippe Jaccottet, desde Hermann Broch y Alexander Blok, hasta Wisława Szymborska. Esta labor, realizada con una convicción admirable y que siempre hemos agradecido los lectores de estas latitudes latinoamericanas, aquella que consiste en creer que con el oficio de la traducción y la edición establecemos vínculos que favorecen la aproximación entre los seres humanos a través de la poesía, también ha sido considerada por nosotros para otorgar nuestro primer Doctorado Honoris Causa en literatura.

El término raro en la literatura, que se alimentó a su vez del de maldito que propuso Paul Verlaine, o del de grotesco de Théophile Gautier, tal como ha evolucionado desde Rubén Darío hasta nuestros días, tiene 
que ver con lo que está fuera del centro. Y el centro, convengámoslo ahora, es el canon. No sé si con esta distinción que la Universidad de Antioquia le concede a Ricardo Cano Gaviria, de su obra desaparezca ese aire de marginalidad que la ha caracterizado desde siempre. La verdad, no lo creo. Ella seguirá, segura de su cualidad independiente, a la espera de los lectores que deseen acercarse a sus ámbitos. En todo caso, a la academia literaria le corresponde criticar, interpretar, analizar, ponderar y elaborar bases serias para que sobre ellas se afinque lo que, en principio, esperamos sea perdurable. Con todo, nuestra valoración se enfrenta ahora a un paisaje que pareciera estar dominado por el poder del periodismo, por el poder de los eventos espectaculares de la literatura, por el poder de los grandes consorcios editoriales, por el poder de esa masa lectora que lee empujada por una propaganda y una publicidad bulliciosas e incesantes. Y no me parece nada aventurado tampoco afirmar que con esta distinción Honoris Causa dada a Ricardo Cano Gaviria, nuestra academia reacciona con inteligencia y sensatez ante este preocupante panorama.

Pero pongamos a un lado esta consideración sobre el canon y aquella literatura que no llama la atención del redil, y pensemos más bien que lo que estamos honrando hoy es una obra sólida y vigorosa que merece nuestra admiración y nuestro aplauso. Con esa certeza los invito a que leamos a Ricardo Cano Gaviria. Y no será arduo concluir no solamente que sus libros son buenos, sino también que él es uno de esos escritores necesarios para las épocas aciagas que vivimos. 